\title{
Materiais didáticos usados em uma escola municipal do Rio de Janeiro, um olhar à luz do tratado da educação ambiental
}

Tainá Figueroa Figueiredo tainaff12@gmail.com 0000-0003-2095-8796 Universidade Federal do Rio de Janeiro, Rio de Janeiro, Rio de Janeiro, Brasil.

Daniel Fonseca de Andrade daniel.andrade@unirio.br 0000-0002-1784-8329

Universidade Federal do Estado do Rio de Janeiro, Rio de Janeiro, Rio de Janeiro, Brasil.

\section{RESUMO}

O presente trabalho visa entender se alguns dos materiais didáticos utilizados em uma escola municipal pública do Rio de Janeiro incorporam os princípios da Educação Ambiental estabelecidos pelo Tratado de Educação Ambiental para Sociedades Sustentáveis e Responsabilidade Global. A técnica de investigação utilizada foi a análise de conteúdo de três materiais, o Projeto Político Pedagógico, Cadernos pedagógicos e Livros do programa 'Cientistas do Amanhã'. Os resultados apontam para o incentivo à educação científica e a ausência da abordagem crítica e política da questão dos conflitos socioambientais locais e de questões relacionadas à justiça. Mesmo assim, conclui-se que os materiais analisados coadunam com alguns princípios do Tratado. Além disso, entendese que é importante que os materiais didáticos, as práticas pedagógicas, a formação das professoras e os documentos institucionais direcionadores do fazer escolar estejam alinhados uns com os outros, e que os princípios da educação ambiental podem ser a base para esse alinhamento.

PALAVRAS-CHAVE: Educação ambiental não formal. Análise de conteúdo. Conflitos. 


\section{A EDUCAÇÃO AMBIENTAL E OS MATERIAIS DIDÁTICOS}

A lei da Política Nacional de Educação Ambiental (PNEA), Lei 9.795/99 (BRASIL, 1999), estabelece que "a educação ambiental é um componente essencial e permanente da educação nacional, e deve estar presente, de forma articulada, em todos os níveis e modalidades do processo educativo".

No município do Rio de Janeiro, o Sistema Municipal de Educação Ambiental (RIO DE JANEIRO, 2008) define a educação ambiental (EA) como um processo contínuo e transdisciplinar de formação e informação, que visa à sustentabilidade através de mudanças de comportamentos e a promoção de atividades que incentivem a participação das comunidades na preservação ambiental, e do desenvolvimento da consciência sobre as questões ambientais (IBID). Deste modo, as políticas públicas apontadas, nacional e municipal, contribuem para a institucionalização da EA, para o aumento da sua visibilidade e adesão pelos diversos setores da sociedade.

Assim como a sociedade é diversa, a EA se caracteriza como um campo múltiplo, contraditório e em construção, habitado por diferentes tendências, com disputas pelos sentidos atribuídos aos termos 'ambiental' (CARVALHO, 2004) e 'educação'. Nessa multiplicidade, há olhares que se orientam pela ação emancipatória, que "encontra na tematização dos conflitos e da justiça ambiental, um espaço para aspirações de cidadania que se constituem na convergência entre as reivindicações sociais e ambientais" (CARVALHO, 2004, p. 19).

A partir da compreensão de algumas características da EA, a reflexão sobre sua prática se torna fundamental. Assim, a prática educativa de uma EA crítica (CARVALHO, 2004) está voltada à "formação do sujeito humano enquanto ser individual e social, historicamente situado" (CARVALHO, 2004, p. 18), e contribuição para uma mudança de valores e atitudes. Neste sentido, Guimarães (2007) considera que a prática educativa deve refletir sobre a origem dos problemas socioambientais do cotidiano e aponta que para a transformação da realidade é importante se pensar sobre o modelo de desenvolvimento da sociedade e as relações de dominação entre indivíduo, sociedade e meio ambiente. Para ele, a EA crítica compreende a sociedade numa perspectiva complexa, em que cada uma de suas partes influencia o todo, mas ao mesmo tempo a sociedade e os padrões sociais influenciam os indivíduos.

Adicionalmente, Andrade e Sorrentino (2013) afirmam que o papel da EA é reconhecer e extrair, de ações do cotidiano, a "hipercomplexidade" do campo pedagógico e, na prática, ir além da resolução de problemas ambientais para incluir os aspectos políticos, filosóficos e científicos relacionados a eles. Desta forma, é importante que os pressupostos da EA e a sua abordagem crítica façam parte de todo o processo educativo e sejam contextualizados à realidade local.

Na prática, entretanto, esses pressupostos teóricos encontram obstáculos a sua aplicação, já que a realidade e o contexto escolar apresentam questões complexas que precisam também ser consideradas, tais quais as limitações encontradas nas escolas, as condições de trabalho dos professores, o universo político na qual estão inseridas, dificuldades no ensino-aprendizagem e, dependendo de onde a prática é realizada, o contexto de violência local e as condições de vida dos estudantes. 
Desta forma, a distância entre discursos, desejos e a prática cotidiana no ambiente escolar pode ser muito grande. Um dos desafios da EA no ensino formal é a sua organização segregada dos conhecimentos e, portanto, a necessidade de mobilização desses saberes fragmentados a fim de formar novos territórios de saberes, mais abertos e dinâmicos, que respondam às necessidades do nosso tempo e às nossas interrogações cognitivas (RODRIGUES, 2014).

No entanto, para a institucionalização da EA na escola pública é importante a participação dos professores, o entendimento do cenário local e das dificuldades do corpo docente no cotidiano escolar (ANDRADE, 2009). Diante do contexto exposto, apesar de haver críticas quanto ao uso de livros didáticos no apoio a EA crítica (MARPICA; LOGAREZZI, 2010), considera-se aqui o material didático como um fator que pode influenciar o desenvolvimento da EA na escola. Isso se justifica pelo fato de ser usado como apoio pedagógico ou direcionar o que será trabalhado em sala de aula. Além disso, Marpica e Logarezzi (2010, p.116) apontam que o livro didático tem um potencial de promover a transversalidade necessária para tratar a questão ambiental, principalmente na perspectiva de "EA problematizadora, crítica e transformadora, ou seja, que encara a questão ambiental atrelada às questões sociais, culturais, éticas e ideológicas".

Adicionalmente, de acordo com Lajolo (1996), o livro didático produz e altera significados, contribui na apropriação e circulação de conhecimento, reproduz e apresenta valores de uma área de conhecimento e do próprio processo de ensino, além de ser um registro temporal com aspecto político e cultural. Assim, é relevante não só pelo aspecto pedagógico, mas também pelas possíveis influências na aprendizagem e desempenho dos estudantes (BONOTTO; SEMPREBONE, 2010).

O presente artigo é fruto de um trabalho de conclusão do curso de graduação em Ciências Ambientais da Universidade Federal do Estado do Rio de Janeiro. Este trabalho surgiu a partir da vivência no projeto de extensão "Aprender brincando com a Natureza: educação ambiental em escolas municipais públicas do Rio de Janeiro", desenvolvido em uma escola localizada numa comunidade do Rio de Janeiro.

A iniciativa para a realização desta pesquisa proveio no terceiro ano de ações desse projeto de extensão, a partir da dificuldade exposta pela coordenadora pedagógica em elaborar o programa de Ciências Naturais para as turmas de alfabetização (primeiro ao terceiro ano). Isso se justifica pela presença apenas de conteúdos de português e matemática nos cadernos pedagógicos fornecidos pela prefeitura do Rio de Janeiro. Diante da atuação da universidade, foi sugerido que os autores conhecessem esses materiais para que colaborassem na inserção do ensino de ciências e da EA nas turmas de alfabetização. A equipe pedagógica recomendou os materiais do projeto Cientistas do Amanhã, pois contribuía no ensino de ciências.

Assim, esta pesquisa tem como objetivo geral entender se a educação ambiental é incorporada em alguns materiais didáticos utilizados nesta escola. Especificamente, visa analisar se o seu Projeto Político Pedagógico (PPP), os Cadernos pedagógicos elaborados pela Secretaria Municipal de Educação do Rio de Janeiro (SME/RJ) e os Livros do programa 'Cientistas do Amanhã' incorporam os Princípios do Tratado de Educação Ambiental para Sociedades Sustentáveis e Responsabilidade Global (FÓRUM..., 1992). 
Este Tratado, fundamental para a EA do Brasil, foi elaborado com participação popular no Fórum das ONGs, em 1992, na Conferência das Nações Unidas sobre Meio Ambiente e Desenvolvimento no Rio de Janeiro. Nele, há princípios e um plano de ação para educadores ambientais (MEC, 1998).

\section{CAMINHOS DA PESQUISA E DA SISTEMATIZAÇÃO}

Este trabalho se caracteriza como uma pesquisa qualitativa (ANDRE, 1995), e foi desenvolvido por meio da técnica de investigação da análise de conteúdo (BARDIN, 1977). A análise do conteúdo dos documentos foi feita a luz dos dezesseis Princípios da Educação Ambiental para Sociedades Sustentáveis e Responsabilidade Global, estabelecidos no tratado de mesmo nome (FÓRUM..., 1992), selecionados por serem reconhecidos como referência por educadores ambientais.

Este estudo seguiu os seguintes passos definidos por Bardin (1977): a escolha dos materiais; a leitura flutuante; a definição de hipótese e objetivo; a definição dos índices, e sistematização de indicadores; a organização e preparação do material para a análise; a leitura atenta dos documentos e busca das palavras exatas, sentidos ou objetivos que convergiam com os índices e princípios; o levantamento de todas as convergências; a análise posterior das convergências com seleção de textos e passagens onde as convergências estavam mais evidentes; categorização, a construção de quadros ilustrativos; apresentação e interpretação dos resultados.

Os documentos estudados nesta pesquisa foram o Projeto Político Pedagógico (PPP) da escola (por indicar as diretrizes da escola), vinte e quatro Cadernos Pedagógicos da Prefeitura Municipal do Rio de Janeiro, referentes ao ensino fundamental I (1음 ao 5o ano) (RIO DE JANEIRO, 2014a, 2014b, 2014c, 2014d, 2014e; RIO DE JANEIRO 2015a, 2015b, 2015c, 2015d, 2015e), e quatro volumes do Programa 'Cientistas do Amanhã' (SANGARI DO BRASIL, 2006a, 2006b, 2006c, 2007) incluídos na pesquisa por serem materiais bastante recomendados na escola. Os resultados dessas análises estão dispostos abaixo.

\section{RESULTADOS}

Para facilitar a visualização completa, os resultados estão dispostos no quadro 1, abaixo. Nele, os 16 princípios do Tratado (coluna '№ do princípio') e os índices extraídos deles (coluna 'Índices') são analisados quanto à presença no Projeto Político Pedagógico (coluna 'PPP', cujos resultados fazem referência às diferentes seções desse documento, $x^{1}$ a $\left.x^{6}\right)$; nos Cadernos Pedagógicos do $1^{\circ}, 2^{\circ}$

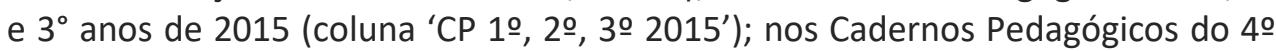
ano de 2015 (coluna 'CP 4ㅇ 2015'); nos Cadernos Pedagógicos do 5o ano de 2015 (coluna 'CP 5o 2015'); e nos diferentes volumes da coleção "Cientistas do Amanhã”, (colunas 'Corpo Humano', 'Ciclos de Vida', 'Solos' e 'Vidas das Plantas', respectivamente).

Após a disposição geral no quadro 1 os resultados são abordados em detalhe para cada um dos materiais estudados, e exemplos de conteúdo dos documentos alinhados aos princípios são destacados, como forma de se ilustrar a análise realizada. Por uma questão de espaço, a inclusão de todos esses alinhamentos 
mostrou-se inviável. Ademais, as linhas horizontais preenchidas com um " $\mathrm{X}$ " representam os índices que foram constatados pelo menos uma vez no material analisado, e os espaços não preenchidos indicam que o índice não foi observado no material. É importante enfatizar que esta é uma análise qualitativa baseada na presença e ausência dos índices, e que em alguns momentos o mesmo índice foi constatado mais de uma vez em atividades ou trechos dos materiais.

Quadro 1. Síntese dos resultados da análise de conteúdo do desenvolvido na pesquisa

\begin{tabular}{|c|c|c|c|c|c|c|c|c|c|}
\hline $\begin{array}{l}\text { Prin- } \\
\text { cípio }\end{array}$ & Índice' & PPPII & $\begin{array}{l}\text { CP } 1^{\circ} \\
2^{\circ}, 3^{\circ} \\
2015^{\prime \prime \prime}\end{array}$ & $\begin{array}{l}\text { CP } 4^{\circ} \\
2015\end{array}$ & $\begin{array}{l}\text { CP } 5^{\circ} \\
2015\end{array}$ & $\begin{array}{c}\text { Corpo } \\
\text { Hu- } \\
\text { mano }\end{array}$ & $\begin{array}{l}\text { Ciclos } \\
\text { de } \\
\text { Vida }\end{array}$ & $\begin{array}{l}5 \\
0 \\
1 \\
0 \\
5\end{array}$ & $\begin{array}{l}\text { Vida das } \\
\text { Plantas }\end{array}$ \\
\hline 1 & $\begin{array}{l}\text { Todos são } \\
\text { aprendizes e } \\
\text { educadores }\end{array}$ & $\begin{array}{l}X^{2} X^{3} \\
X^{4} X^{5}\end{array}$ & & & $x$ & $x$ & $x$ & $x$ & $\mathrm{x}$ \\
\hline 2 & $\begin{array}{c}\text { Pensamento } \\
\text { crítico e inovador } \\
\text { - transforma-ção } \\
\text { social }\end{array}$ & $\begin{array}{l}X^{1} X^{2} \\
X^{4}\end{array}$ & & & $\mathrm{X}$ & $\mathrm{x}$ & $\mathrm{x}$ & $x$ & $\mathrm{x}$ \\
\hline 3 & Consciência Local & $\begin{array}{l}X^{1} X^{2} \\
X^{3} \\
X^{4} \\
\end{array}$ & $x$ & $\mathrm{x}$ & $\mathrm{x}$ & $x$ & $x$ & $\mathrm{x}$ & $\mathrm{x}$ \\
\hline 4 & $\begin{array}{l}\text { Ato político - } \\
\text { Transformação } \\
\text { social }\end{array}$ & $\begin{array}{l}X^{1} X^{2} \\
X^{4}\end{array}$ & & & & & & & \\
\hline 5 & $\begin{array}{c}\text { Holística - } \\
\text { Interdisciplinar }\end{array}$ & $\begin{array}{l}X^{1} X^{2} \\
X^{4} \\
X^{5} \\
\end{array}$ & $x$ & $X$ & $X$ & $x$ & $\mathrm{x}$ & $x$ & $x$ \\
\hline 6 & $\begin{array}{l}\text { Solidariedade, } \\
\text { igualdade, } \\
\text { respeito, } \\
\text { interação entre } \\
\text { culturas }\end{array}$ & $\mathrm{X}^{1} \mathrm{X}^{2}$ & $x$ & & & & & $\mathrm{x}$ & $\mathrm{x}$ \\
\hline 7 & $\begin{array}{c}\text { Inter-relação, } \\
\text { democracia, } \\
\text { fome, degradação } \\
\text { da flora e fauna }\end{array}$ & & & & $\mathrm{X}$ & $\mathrm{x}$ & $\mathrm{x}$ & $x$ & $x$ \\
\hline 8 & Cooperação & $x^{2} x^{6}$ & & & & $\mathrm{x}$ & & $x$ & \\
\hline 9 & $\begin{array}{c}\text { Reflexão e } \\
\text { respeito à história } \\
\text { indígena e } \\
\text { culturas locais }\end{array}$ & $\begin{array}{l}X^{1} X^{2} \\
x^{6}\end{array}$ & $x$ & $x$ & $x$ & & & $x$ & $x$ \\
\hline 10 & $\begin{array}{c}\text { Poder / } \\
\text { autonomia / } \\
\text { Empoderamento }\end{array}$ & $\begin{array}{l}X^{2} x^{4} \\
x^{5}\end{array}$ & $x$ & $x$ & & & & & \\
\hline 11 & $\begin{array}{c}\text { Valorização de } \\
\text { diferentes formas } \\
\text { de conhecimento }\end{array}$ & $\begin{array}{c}x^{2} \\
x^{5} x^{6}\end{array}$ & & & & $\mathrm{x}$ & & & \\
\hline 12 & Conflitos / Justiça & & & & & & & & \\
\hline 13 & $\begin{array}{c}\text { Cooperação e } \\
\text { diálogo }\end{array}$ & $\begin{array}{l}X^{2} X^{4} \\
x^{5} \\
\end{array}$ & & & & $x$ & $x$ & $x$ & $x$ \\
\hline 14 & $\begin{array}{l}\text { Comunicação e } \\
\text { democratização } \\
\text { dos meios de } \\
\text { comunicação }\end{array}$ & $x^{2}$ & & & & $x$ & $\mathrm{x}$ & $x$ & $x$ \\
\hline 15 & $\begin{array}{l}\text { Integração de } \\
\text { conhecimentos }\end{array}$ & $\begin{array}{l}X^{2} X^{4} \\
X^{6} \\
\end{array}$ & $x$ & $x$ & $x$ & $x$ & $x$ & $x$ & $x$ \\
\hline 16 & Consciência ética & & $X$ & & & & $X$ & $X$ & $X$ \\
\hline
\end{tabular}




\begin{tabular}{|l|c|l|l|l|l|l|l|l|l|}
\hline & $\begin{array}{c}\text { sobre as formas } \\
\text { de vida. }\end{array}$ & & & & & & & & \\
\hline
\end{tabular}

Fonte: Elaborado pelos autores.

\section{APRESENTAÇÃO DAS ANÁLISES POR MATERIAL PEDAGÓGICO ESTUDADO e DISCUSSÃO}

\section{PROJETO POLÍTICO PEDAGÓGICO (PPP) ${ }^{\mathrm{IV}}$}

O PPP foi elaborado em agosto de 2011. Nele, a escola se define como "A escola que diz sim a vida", em alusão ao educador Paulo Freire. A fim de se conhecer como a escola percebia o seu papel em relação à EA, todo o documento foi analisado. Entretanto, apenas os capítulos 'Objetivos', 'Metodologia', 'Metas' e 'Atividades' foram destacados, por representarem as diretrizes adotadas e indicarem os rumos a serem tomados pela equipe escolar ao longo da vigência do documento.

Como resultado, foi constatado na análise que o PPP incorpora alguns elementos que podem ser associados aos princípios da EA. Por exemplo, quando o documento aponta a importância do pensamento crítico e inovador visando à transformação social (relacionado, portanto, aos princípios 2 e 4 do Tratado), e o desenvolvimento de valores como solidariedade, igualdade e respeito (princípio 6), como pode ser observado do trecho de apresentação do PPP a seguir:

\footnotetext{
O Projeto Político Pedagógico da Escola pretende se pautar numa análise estrutural de ruptura/transformação da sociedade existente, não a reproduzindo, mas sinalizando a antecipação de uma sociedade mais igualitária, solidária, de modo que favoreça o desenvolvimento da consciência crítica cidadã, para qual o acesso, o desenvolvimento e a apropriação do código escrito e a evolução dos conceitos relacionados com a vida e as formas democráticas de transformá-la sejam ferramentas essenciais nesse caminhar.
}

Ademais, o documento apresenta quatro objetivos gerais nos quais foram também identificadas mensagens que coadunam com princípios ( $X^{1}$ no quadro acima). No primeiro objetivo, destacado a seguir, foram identificados índices relativos aos princípios 2 e 4, sobre pensamento crítico, transformação social e política.

\footnotetext{
garantir espaços e tempos permanentes de estudo e discussão de princípios filosóficos, políticos e culturais com todos os segmentos, para que seja assegurada e viabilizada uma possibilidade de transformação, sempre com o movimento ação - reflexão - ação.
}

Já no segundo objetivo, "assumir a opção pela ruptura/transformação como um processo, que está sempre se fazendo, se ' $r$ ' fazendo e nunca está terminado", foi estabelecida uma relação com o índice do princípio 2 . 0 terceiro objetivo do documento, "assumir uma abordagem holística da criança, encarando-a como um todo; corpo, mente, emoções, criatividade, história e identidade social", com o índice "perspectiva holística da educação" (associado ao índice do princípio 5); e o quarto, "conhecer a heterogeneidade do povo brasileiro como um acervo a ser preservado", com índices relacionados aos 
princípios 3, 6 e 9, que se referem à consciência local, ao respeito, à interação entre culturas e à cultura local.

Se nas análises dos Objetivos Gerais do PPP não encontramos muitas associações entre seus conteúdos e os índices extraídos dos Princípios do Tratado de $E A$, pode-se dizer que elas são compensadas pelos objetivos específicos $\left(X^{2}\right)$ : em treze deles há referências diretas a esses índices. Como pode ser visto no quadro 1, os 'Objetivos Específicos' foi a seção do documento que mais se alinhou aos Princípios como um todo, com ausências constatadas apenas dos princípios 7, 12 e 16. Um exemplo aqui destacado é o terceiro objetivo específico "desenvolver a autonomia, a criatividade e espírito crítico nos alunos considerando que cada um é sujeito de sua aprendizagem, ainda que necessite da mediação (dos mais experientes) para avançar no processo", o qual incorpora a questão de que todos são aprendizes e educadores (princípio 1), que o pensamento crítico deve ser fomentado pela escola (princípio 2), que a aprendizagem é individual e coletiva, e com foco na consciência local (princípio 3), e que propõe o incentivo a construção de autonomia nos estudantes, indiretamente motivando o seu empoderamento (princípio 10).

Adicionalmente, no capítulo sobre metodologia (identificado como $\mathrm{X}^{3}$ no quadro) é descrito como deve ser pautado o objetivo principal da ação pedagógica. Aqui, foram constatados alinhamentos com os princípios 1 e 3 , pois enfatiza a valorização do conhecimento do estudante e a construção do conhecimento através da parceria aluno-professor, o que aloca, ao mesmo tempo, o docente em um papel de parceiro, de observador e de pesquisador das atividades escolares. Também orienta que o professor priorize a observação, pesquisa e desafios no ambiente escolar ou externo para a construção do conhecimento.

Já as metas do PPP, representadas no quadro por $X^{4}$, consistem nas habilidades e competências que a escola deseja fomentar junto aos discentes. São exemplos dessas habilidades e competências: analisar, comparar e interpretar fatos, decidir, planejar e trabalhar em grupo, calcular, dominar a leitura e a escrita, desenvolver o hábito de estudar e conscientizar sobre a importância da aprendizagem. Além disso, a seção destaca como meta a atuação do professor como um orientador e motivador da aprendizagem, e o estímulo ao empoderamento dos estudantes através das linguagens e meios de comunicação. Também, indica a importância de os estudantes desenvolverem a capacidade de compreender e atuar no seu entorno social como cidadãos, e a construírem autonomia. Em relação aos princípios da EA, essas são metas alinhadas aos princípios 1, 2, 3, 4, 5, 10, 13 e 15 .

O capítulo seguinte, seção 'Avaliação' ( $X^{5}$ no quadro) do PPP, dispõe sobre a forma de avaliação dos estudantes e do próprio PPP. Nesse, foi possível constatar pressupostos alinhados aos Princípios do Tratado (1, 5, 10, 11 e 13). Como ilustração dessas relações, pode-se destacar aqui, por exemplo, a valorização do conhecimento do estudante como ponto de partida para a avaliação da aprendizagem; a relação entre planejamento, ensino e aprendizagem; a autonomia do docente para a construção de mecanismos de intervenção no processo de construção do conhecimento; a promoção de avaliações dialógicas; a visão transdisciplinar; e o movimento de ação - reflexão - ação sugerido para o processo avaliativo. 
Nos capítulos finais do documento, denominados 'Atividades', 'Ações para a construção e o desenvolvimento da aprendizagem nas diferentes áreas', 'Utilização dos espaços', e 'Temas integrados', não foram observadas relações com os Princípios. No entanto, é importante ressaltar que, ao final, no capítulo 'Entendendo a nossa escola' $\left(X^{6}\right)$, é reafirmado que a instituição deve valorizar a realidade local (Princípio 3) e adequar o seu currículo inclusive a essas necessidades, além de estimular o planejamento coletivo do ensino. Essas práticas estão alinhadas aos Princípios 8, 9, 11 e 15, que como pode ser visto no quadro acima, versam sobre a cooperação, a valorização das culturas locais, e a valorização e integração das diversas formas de conhecimento.

A partir dos resultados supracitados destaca-se a incorporação dos princípios do Tratado em quase todos os objetivos gerais e específicos do PPP, exceto os referentes ao posicionamento político, aos conflitos e ao desenvolvimento de uma consciência ética sobre as formas de vida. Também estão incorporados nos tópicos 'Metodologia', 'Metas' e 'Avaliação'. Nesses, é incentivada a parceria professor - aluno, pois contemplam o docente numa posição de orientador, pesquisador e motivador da aprendizagem, valorizando o seu trabalho e o conhecimento de todos os envolvidos. A avaliação dialógica em um movimento de ação - reflexão - ação é proposta, com visão transdisciplinar, contribuindo não só na aprendizagem e empoderamento dos estudantes, mas também na autoestima dos docentes. Assim, esse documento assume a natureza holística da criança, valoriza o conhecimento do estudante e a construção do conhecimento através da parceria aluno-professor.

Entretanto, observam-se algumas limitações nesses materiais, como a ausência do termo 'educação ambiental' e a presença de referências a questões ambientais apenas no tópico 'Ações para a construção e o desenvolvimento da aprendizagem nas diferentes áreas' do PPP, que propõe o seu desenvolvimento apenas em feiras de ciências e campanhas de preservação ambiental. Segundo a PNEA (BRASIL, 1999), a EA deve ser inserida no ensino formal de forma permanente e contínua e não apenas pontualmente, como sugere o PPP. Considerando que a abordagem pedagógica contínua das questões ambientais de fato já acontece na escola, esse princípio poderia ser refletido de forma explícita no PPP. Neste contexto, surpreende a ausência completa de referências à 'educação ambiental' e ao 'meio ambiente' no documento, uma vez que a comunidade onde a escola está inserida possui diversos movimentos e lideranças relacionados ao meio ambiente.

Outra limitação desse documento é a ausência de manifestações aos Princípios da EA nos outros capítulos do PPP, 'Atividades', 'Ações para a construção e o desenvolvimento da aprendizagem nas diferentes áreas', 'Utilização dos espaços' e 'Temas integrados'. Os Princípios podem, sempre que possível, permear todo o documento, pois coadunam com outros princípios propostos pela educação e pela escola. O reconhecimento da importância de se carregar esses princípios por todo o documento incorpora sentido a inserção da EA de forma integral e institucionalizada. 


\section{CADERNOS PEDAGÓGICOS}

Além do PPP, foram analisados comparativamente quarenta cadernos pedagógicos fornecidos e elaborados pela equipe da Secretaria Municipal de Educação do Rio de Janeiro, do primeiro ao quinto ano do ensino fundamental, referentes a 2014 e 2015 (vinte e quatro volumes referentes à Alfabetização e dezesseis à disciplina de Ciências).

\section{CADERNOS DA ALFABETIZAÇÃO DE 2014 E 2015}

Nesta investigação, foi realizada uma análise comparativa dos conteúdos dos cadernos da alfabetização (primeiro, segundo e terceiro anos) referentes aos anos de 2014 (RIO DE JANEIRO, 2014a; 2014b; 2014c) e 2015 (RIO DE JANEIRO, 2015a; 2015b; 2015c), apresentadas na quarta coluna (denominada CP $1^{\circ}, 2^{\circ} 3^{\circ}$ anos 2015) do Quadro 1.

Esses cadernos são divididos em bimestres e incorporam conteúdos de português e matemática de forma integrada através da interpretação de textos, jogos e brincadeiras. Essa organização pode ser considerada uma experiência interdisciplinar (princípio 5) e também é possível observar propostas que incentivam o desenvolvimento de uma consciência ética (princípio 16).

Apesar desses materiais não se proporem a abordar os conteúdos de ciências, foram constatados assuntos dessa temática em forma de notas, curiosidades, textos e exercícios. Também não se observou modificação no conteúdo dos cadernos de 2014 para 2015, que de forma geral desenvolvem os assuntos de português e matemática de forma contextualizada com parte da realidade da cidade.

Além disso, em algumas atividades os estudantes eram incentivados a observar o entorno da escola e sua disposição na sala de aula. Por exemplo, no caderno do terceiro ano do primeiro bimestre de 2015 (RIO DE JANEIRO, 2015c), há uma proposta pedagógica alinhada ao princípio 3, de observar e registrar a natureza, construções e meios de transporte ao redor da escola, e de refletir em conjunto sobre soluções e ações para prevenção da dengue (IBID). 0 desenvolvimento dos temas folclore, brincadeiras, cultura indígena e amizade foram bastante observados na maioria dos cadernos analisados, muitos deles sendo desenvolvidos ao longo do ano através de textos e atividades lúdicas, comparando brincadeiras antigas, atuais e indígenas, sendo esse um exemplo de valorização da cultura local e indígena, alinhando-se assim aos princípios 6 e 9 .

No entanto, alguns princípios não foram contemplados nos cadernos da alfabetização, como, por exemplo, os princípios 1, 2, 4, 7, 8, 10 e 13. Já o princípio 14 estava apenas brevemente incorporado.

Quanto aos cadernos de ciências, foram analisados os do quarto e quinto anos referentes a 2014 (RIO DE JANEIRO, 2014d; 2014e) e 2015 (RIO DE JANEIRO, 2015d; 2015e). A análise desses cadernos justificou-se pelo fato da disciplina ser considerada pelas docentes a mais próxima da EA.

De maneira geral, não foram observadas muitas mudanças entre os cadernos de ciências dos dois anos analisados. Devido a isso, estão destacados aqui e no quadro 1, apenas exemplos referentes aos materiais de 2015. Uma das principais 
alterações constatadas foi a redução do número de experimentos práticos propostos, do ano de 2014 para 2015. Além disso, observou-se a reorganização de temas e atividades, a abordagem de temas ambientais contextualizados à realidade da cidade, e conteúdo de outras disciplinas incorporados de forma interdisciplinar, como será visto abaixo.

\section{CADERNOS DE CIÊNCIAS DO QUARTO ANO DE 2015}

Em relação ao Tratado, no material de 2015 do quarto ano (RIO DE JANEIRO, $2015 \mathrm{~d}$ ), foram constatados conteúdos que remetem aos princípios (sintetizados, no Quadro 1 , na coluna 'CP $4^{\circ}$ ano $2015^{\prime}$ ) relacionados ao desenvolvimento de uma consciência local e ética às formas de vida (3 e 16), a integração de conhecimento e abordagem interdisciplinar (15 e 5), e incorporação da cultura indígena (9).

Assim como nos materiais anteriores, não foram constatadas passagens alinhadas a todos os princípios, sendo interessante a reflexão sobre a ausência dos princípios relacionados a conflito (12), empoderamento (10), troca de experiências (1 e 11), comunicação (14) e incentivo ao pensamento crítico (2), uma vez que esses índices fazem parte do cotidiano local e são importantes na busca da transformação social.

Além disso, é relevante destacar que os cadernos abordavam ambientes, ecossistemas, biodiversidade, folclore e músicas tradicionais da cidade do Rio de Janeiro, possibilitando o estímulo de um sentimento de pertencimento nos estudantes e um incentivo para que conheçam o local onde moram, apesar de não estarem contextualizados diretamente com a realidade da comunidade onde a escola está localizada. Quanto à temática ambiental, a existência no material de temas próximos à realidade da comunidade, como abastecimento de água, deslizamento de terra e a convivência com animais da Mata Atlântica nas casas de moradores, aproxima o conteúdo aos estudantes, que vivem próximo a uma unidade de conservação. Entretanto, o material aborda questões ambientais importantes como desmatamento, aquecimento global, consumo, extinção de espécies, agrotóxicos de forma passageira e pouco crítica.

Embora tenham sido percebidas poucas mudanças entre o material de 2014 e 2015, algumas propostas e experimentos interessantes foram retirados. Por exemplo, um texto que versava sobre os materiais que constituem os objetos e que relacionava o modo de vida do humano primitivo à história e ao progresso. Este mesmo texto propunha uma reflexão sobre a origem das coisas e sugeria a construção coletiva de uma composição orientada pelas seguintes questões: "O que ganhamos com o progresso? O que perdemos com o progresso?" (RIO DE JANEIRO, 2014d, 3 bimestre, p.36). Tal abordagem contribui para a formação do senso crítico sobre o desenvolvimento e suas implicações, sobre a influência humana no ambiente e a busca da origem de problemas vivenciados atualmente, temas essenciais para a EA como colocado por Guimarães (2007) acima.

\section{CADERNOS DE CIÊNCIAS DO QUINTO ANO DE 2015}

Os princípios constatados nos materiais do quinto ano de 2015 (RIO DE JANEIRO, 2015e) estão apresentados no quadro 1, na sexta coluna chamada 'CP 
5o ano 2015'. Na análise desses materiais, foram constatadas aproximações aos princípios semelhantes às encontradas no material do quarto ano. Desta forma, foi possível observar a existência de propostas de experimentação e observação sobre processos e fenômenos naturais locais de forma integrada (princípio 3 e 15), a abordagem de fatos históricos da cidade atrelados às culturas locais, saúde e diversidade de forma interdisciplinar (9 e 15), mas poucas atividades com uma abordagem crítica e incentivo ao compartilhamento de conhecimento.

Sobre esse compartilhamento de saberes na aprendizagem, destaca-se o texto do início desse caderno pedagógico (RIO DE JANEIRO, 2015e, 4 o bimestre), feito por um aluno da rede municipal de ensino, que relaciona a escola a uma orquestra. A inserção desse texto no caderno valoriza o trabalho desenvolvido pelos estudantes, motiva a construção de um senso de pertencimento e aponta para uma proposta integradora.

Diante dos resultados mencionados acima, ao comparar os materiais de ciências com os outros cadernos analisados, observaram-se sugestões de lugares para se visitar e de endereços na Internet para se pesquisar, abordagens de questões locais e contextualizadas a cidade, e de temas ambientais. Entretanto, esses temas não são desenvolvidos completamente de forma crítica, pois não incentivam o questionamento da realidade local e a problematização sobre a origem dos problemas socioambientais locais relacionada a questões históricas, políticas e sociais. Além disso, destaca-se a valorização da diversidade cultural brasileira através de brincadeiras, folclore e receitas típicas, principalmente naqueles destinados à alfabetização.

Quanto aos Princípios, houve maior consonância nos conteúdos encontrados nos cadernos de ciências do que nos de alfabetização (fazendo-se uma comparação entre as três colunas analisadas). Todavia, novamente, conteúdos com referência a questão do conflito (12) e de posicionamentos políticos (4) não foram encontrados. É importante frisar que a incorporação dos Princípios nos cadernos pedagógicos analisados é entendida como positiva, e que a convergência do material com os Princípios demonstra a valorização das professoras como mediadoras na aprendizagem, da abordagem interdisciplinar, da diversidade cultural e das questões ambientais contextualizadas à realidade carioca, princípios esses manifestados em experimentos e atividades que incentivam a aproximação dos estudantes ao local em que vivem.

Por fim, a ausência de modificações nos cadernos pedagógicos de alfabetização produzidos pela SME/RJ, do ano de 2014 para 2015, é considerada uma limitação. Isso chama atenção diante do avanço do conhecimento e da reflexão sobre a atualização desses materiais. Nos cadernos de ciências analisados foram constatadas muitas mudanças entre os referidos anos, não só na parte gráfica, mas nos conteúdos, experimentos e atividades. Além disso, a baixa incorporação dos Princípios nos cadernos pedagógicos analisados é considerada como uma limitação dos mesmos.

\section{LIVROS DO PROGRAMA 'CIENTISTAS DO AMANHÃ’}

O Programa Cientistas do Amanhã, concebido e realizado pelo Centro de Pesquisa e Desenvolvimento da Sangari Brasil, foi executado na escola de 2009 a 2012 através de uma parceria público-privada. Apesar de não mais fazer parte da 
rotina escolar, os livros do professor (utilizados na análise) e do aluno, e materiais para experimentos, ainda permanecem na escola e nas suas salas de aula.

Nesta investigação foram analisados os conteúdos de quatro livros destinados às docentes (apresentados no quadro 1). A escolha destes materiais foi sugerida pelas professoras e coordenadora pedagógica para uma melhor compreensão sobre o funcionamento desse projeto e de seus experimentos, e por elogiarem bastante o programa, pois contribuía para a inserção dos conteúdos de ciências de forma prática. Outra justificativa foi a relação desses temas com os conteúdos de ciências definidos para serem trabalhados no ano de 2015, e os temas das atividades de EA desenvolvidos com as turmas do 4ㅇ e 5o anos pelo projeto de extensão, 'Aprender Brincando com a Natureza'. Abaixo serão descritos os resultados das análises para cada uma das obras.

\section{LIVRO 'CORPO HUMANO’}

O livro 'Corpo Humano' (SANGARI DO BRASIL, 2006b) é indicado pelos seus autores para estudantes do quinto ano do ensino fundamental. Esse exemplar visa desenvolver a responsabilidade e os cuidados com o corpo humano; abordar os sistemas de forma integrada, nutrição, reprodução, e constituição do organismo; e a saúde e o bem-estar físico e mental através de experimentos que ilustram o seu funcionamento.

No diagnóstico, apontado na sétima coluna do Quadro 1, observou-se que o docente é instruído a incentivar os estudantes a refletir sobre os temas e os seus hábitos, pesquisar e conhecer as etapas do método científico clássico, se comunicar, discutir e compartilhar suas dúvidas e conhecimentos construídos, e trabalhar em equipe. Quanto aos princípios, o livro apresenta uma abordagem ampla, holística e interdisciplinar dos temas, visando não só o autoconhecimento, mas também comparações entre o organismo humano e de outros seres vivos, 0 que traz alinhamento com os princípios 5 e 15.

Além disso, durante as sugestões de atividades, os estudantes são incentivados a dialogar, debater ideias, cooperar, trabalhar em equipe (princípios 8 e 13), relacionar o estudo do corpo com alimentação e bem-estar, e a problematizar a questão da saúde biológica e emocional (princípio 7). Os princípios 2 e 11 são também contemplados nessa edição, ao incentivar uma aprendizagem coletiva baseada na troca e construção de conhecimento entre o professor e o estudante valorizando seus saberes.

O livro motiva também a observação e registro científico dos experimentos que são elaborados. Entretanto, como um manual, é interessante como inspiração, mas reduz o docente a um executor. Da mesma forma, não se aprofunda nas questões sociais e culturais na proposta sobre identidade e não se posiciona sobre o tema discriminação.

\section{LIVRO 'CICLOS DE VIDA’}

Já o livro sobre o tema 'Ciclos de Vida' é indicado para as turmas do terceiro ano do ensino fundamental e se define, assim como os outros, "como um material formativo que apoia os professores no planejamento e desenvolvimento 
das Unidades em relação aos conteúdos abordados e a metodologia CTC" (SANGARI DO BRASIL, 2006a, p. 9). Esse livro aborda os seguintes tópicos: caracterização de um ser vivo; conceito de ciclo de vida; metamorfose; extinção; reprodução relações entre seres vivos e meio ambiente; biodiversidade e conservação da vida; observação e investigação. Ele sugere estratégias didáticas como jogos em ambiente natural, análise de imagens, debates em grupo sobre situações problemas, e montagens de experimentos, como por exemplo, o minhocário.

A análise quanto aos princípios, apresentada na oitava coluna do Quadro 1, constatou que as propostas desse volume incentivam a troca de experiências entre estudantes e professor (princípio 1), o pensamento crítico (princípio 2) através de questionamentos sobre fenômenos naturais e cotidianos, a aprendizagem coletiva, e a reflexão sobre questões locais do entorno da escola (princípio 3).

Adicionalmente, os assuntos são abordados de forma interdisciplinar (princípio 5) destacando a inter-relação entre os temas (princípio 7), uma vez que abordam os ciclos de vida de várias espécies de forma comparativa, os ambientes onde vivem e os respectivos problemas ambientais aos quais são expostas.

A convergência com outros princípios foi constatada no decorrer da análise, pois as crianças são motivadas a cooperar para desenvolver os experimentos e posteriormente registrar e trocar experiências sobre o observado (princípios 8 e 13). O incentivo a escrita ocorre através dos registros sobre os experimentos, os desenhos, e habilidades manuais (princípio 15), pois integra conhecimentos e aptidões. Por fim, foi observado um estímulo à construção de uma consciência ética através da compreensão das inter-relações das espécies e a necessidade de preservação dessas (princípio 16).

Assim como o volume anterior, esse livro apresenta experimentos interessantes. Porém, é um manual, e demanda tempo para planejamento, desenvolvimento e acompanhamento dos experimentos. Considerando-se o tema, destaca-se a ausência dos princípios relacionados à interação entre culturas e diversidade cultural (9) e a conflitos (12), pois não só fazem parte da vida humana e de outros seres vivos, mas são também importantes para as realidades de muitas escolas, a exemplo da escola na qual esta pesquisa foi realizada.

\section{LIVRO 'SOLOS'}

O livro 'Solos' é indicado para o quinto ano do ensino fundamental e visa trabalhar o solo como um sistema vivo e dinâmico, seus componentes, formação, características, ciclagem de nutrientes, sua relação com os seres vivos, usos, preservação, erosão e agrotóxicos (SANGARI DO BRASIL, 2007).

À luz dos princípios do Tratado, na nona coluna do Quadro 1, este material estimula a troca de experiências e conhecimentos entre os estudantes e os docentes, cooperação e debates (princípios 1, 8, 13). Em alguns momentos, incentiva o pensamento crítico sobre as questões ambientais relacionadas à ocupação do solo, erosão e escoamento superficial, e um pouco sobre agricultura, problematizando a interferência humana (princípio 2). Além disso, propõe o debate sobre a percepção do entorno através de experimento com 
amostras de solo locais (princípio 3). Também, incentiva a leitura e produção de textos através dos registros dos experimentos, construção de gráficos e tabelas através de artes e conceitos de geografia, e aborda a relação do solo com o ser humano e outros seres vivos de forma interdisciplinar (princípio 5 e 15). Ademais, aborda os temas população, saúde e degradação da flora e fauna relacionados ao solo (princípio 7).

Adicionalmente, foi possível observar que o livro incorpora questões culturais (princípio 9), e em todas as aulas constatou-se a busca para que os estudantes percebessem o solo como um sistema vivo e importante para a vida (princípio 16). Diante dos princípios, esse volume é bem completo e contempla importantes questões ambientais relacionadas ao tema. Porém, não aborda os conflitos existentes na área rural, a pressão exercida pelo agronegócio, monoculturas, a especulação imobiliária em biomas brasileiros, nem a importância da área rural para a alimentação.

\section{LIVRO 'VIDA DAS PLANTAS'}

O último livro analisado foi o 'Vida das plantas' (SANGARI DO BRASIL, 2006c). Esse material objetiva trabalhar a estrutura, função, nutrição e reprodução das plantas, a interdependência entre plantas e outros seres vivos, a valorização da biodiversidade, os problemas ambientais, e as habilidades de observação e investigação (SANGARI DO BRASIL, 2006c).

Sob a ótica dos princípios, observou-se que muitos são contemplados, conforme sintetizado na última coluna do Quadro 1. Há um incentivo ao compartilhamento de conhecimento entre estudantes e professores através de debates sobre os experimentos e assuntos desenvolvidos. O docente também é motivado a ouvir os questionamentos e impressões dos estudantes e a trabalhar em equipe (princípios 1 , 8 e 13).

Além disso, há a sugestão para o desenvolvimento de uma feira de Ciências para divulgação dos registros do 'diário de ciências' e experiências dos estudantes (princípio 1). O pensamento crítico é estimulado em algumas propostas, principalmente quando os estudantes são instigados a refletir sobre as causas e soluções dos problemas locais (princípios 2 e 3). A abordagem é bastante interdisciplinar, e também motiva o desenvolvimento de algumas habilidades nos estudantes, como a observação, desenho, e capacidade de integrar os conhecimentos relacionados às plantas (princípios 5 e 15). Da mesma forma, há referência aos costumes indígenas de se utilizar a semente de urucum para se pintar (SANGARI DO BRASIL, 2006c), o que se alinha aos princípios 6 e 9, a importância da saúde das plantas e sua relação com a saúde humana, e a degradação da biodiversidade (princípio 7). Por fim, observou-se um posicionamento a favor de uma consciência ética (princípio 16) ao incentivar a preservação dos seres vivos e o destaque para a interdependência das espécies.

Diante da análise dos resultados apontados acima, ressalta-se a semelhança dos materiais do 'Cientistas do Amanhã' e dos cadernos pedagógicos de ciências da prefeitura quanto à presença considerável de experimentos. Isso possibilita a vivência do método científico para registro e compreensão de fenômenos 
Nesse sentido, eles cumprem o seu objetivo no incentivo e desenvolvimento do método científico clássico como didática, uma vez que nas propostas dos temas, os estudantes são orientados a seguir um roteiro, pensar em situações problema, desenvolver hipóteses e soluções, fazer experimentos, observar, e registrar as suas percepções e observações no 'Diário de Ciências'.

A experimentação é uma das principais metodologias dos materiais do 'Cientistas do Amanhã' e foi elogiada pelas docentes, pois envolvia e despertava a curiosidade dos estudantes, e facilitava a abordagem dos conteúdos de ciências. Além disso, essa percepção também foi constatada no projeto, 'Aprender brincando com a Natureza', que verificou que experimentos, metodologias e atividades participativas despertam maior interesse, por transformar os envolvidos em atores na construção do conhecimento (FIGUEIREDO; PINHEIRO; ZAÚ, 2014).

Além disso, Rocha e Santos (2010), ao pensar sobre a experimentação no ensino de ciências, apontaram como um novo paradigma abordagens centradas nos fenômenos, tendo a problematização do cotidiano como ponto de partida para os conteúdos. Dessa forma, a experimentação é indicada como uma forma de integrar o conhecimento formal e o ambiente, gerando motivação e desestabilização de conhecimentos, o estímulo ao levantamento de hipóteses, a valorização do pensamento crítico e divergente, com liberdade de expressão, a compreensão do ambiente na sua complexidade, e o tratamento de conceitos como provisórios e em permanente construção (ROCHA; SANTOS, 2010).

Entretanto, um aspecto negativo associado à experimentação é a configuração dos livros do 'Cientistas do Amanhã' como manuais de atividade ou protocolo de experimentos, pois possuem cronograma e continuidade, demandando das docentes maior tempo de dedicação aos experimentos. Este formato contribui para a subutilização do trabalho intelectual do professor, uma vez que o livro aponta o embasamento teórico, o material necessário, o método, e como deve ser a avaliação dos estudantes, transformando o docente em um mero executor de tarefas. Uma passagem do texto que ilustra o que foi dito, por exemplo, é quando questiona a docente: "Você conseguiu ouvir os alunos e aproveitar seus questionamentos para fazer questionamentos e aproveitar o tema? Proporcionou momentos de troca de ideias entre os grupos?" (SANGARI DO BRASIL, 2006a, p. 55). Outra, quando indica para a professora que "controlar periodicamente a produção dos alunos no diário de ciências é fundamental para o desenvolvimento da mostra de ciências e principalmente para o aprendizado dos alunos" (SANGARI DO BRASIL, 2007, p.47).

Esse comportamento de prescrever todas as ações pedagógicas pode sobrecarregar e limitar o educador, e não é coerente com o objetivo do programa, que visa o ensino de ciências com criatividade. Assim como Piccinini (2013) observou, há pouco espaço para a inventividade, tanto no trabalho das professoras quanto no dos estudantes diante do modelo de conduta préestabelecido: "peguem, encostem, observem, afastem, posicionem, refaçam" (PICCINNI, 2013, p. 6). Assim, embora vise desenvolver o pensamento científico através da experimentação, pode levar a um efeito reverso, pois não estimula a criatividade e nem o pensamento crítico.

Adicionalmente, o Programa Cientistas do Amanhã instalou armários com os materiais necessários para as atividades propostas nos materiais. Na escola 
estudada, foi observado que após o seu término esses materiais ficaram no local, mas houve dificuldade em manter as propostas do programa nas práticas pedagógicas. Uma das razões para isso é a presença de uma instrutora durante a vigência do programa, que auxiliava as professoras no desenvolvimento das atividades, não as empoderando a desenvolver suas próprias pedagogias. Essa é mais uma consequência de um programa que não desenvolve a autonomia das docentes para o uso do material e que praticamente condiciona a sua execução bem-sucedida à dependência de ajuda externa.

Outro aspecto a ser realçado é a organização dos livros do 'Cientistas do Amanhã', que apresentam continuidade entre os conteúdos e sequência de propostas direcionadas a séries pré-definidas, e estabelecem relações entre os volumes e suas atividades. Além disso, a ausência da questão cultural no livro 'Ciclos de Vida', do 'Cientistas do Amanhã' é um obstáculo, pois apesar de apresentar uma abordagem holística e comparar os ciclos de vida de diversos seres vivos, ao abordar o ciclo de vida humano não incorpora nele os seus aspectos culturais.

Adicionalmente, os materiais analisados dos livros do Programa 'Cientistas do Amanhã' apresentam uma abordagem profunda, interdisciplinar e holística dos temas propostos, e incorporam a maioria dos princípios, exceto os relativos a posicionamento político e a conflitos, principalmente nos livros sobre 'Solos' e 'Vida das Plantas'. Assim, esses materiais focam em possibilitar que os estudantes aprendam através da prática, da observação de fenômenos e do seu próprio corpo, com um olhar científico, a fim de criar a experiência de laboratório dentro da sala de aula. No entanto, apresenta um lado negativo que é o seu foco em conteúdos e procedimentos de pesquisa, não deixando muito espaço para a criatividade das docentes e dos estudantes.

\section{ALGUMAS RELAÇÕES ENTRE OS MATERIAIS ANALISADOS}

A partir da análise dos materiais foi possível observar algumas relações entre eles, que serão discutidas separadamente aqui.

Os três grupos de materiais estudados compartilham dois pontos relevantes, a interdisciplinaridade e a valorização do local. Em todos os materiais analisados ficou evidente a abordagem interdisciplinar dos temas, possibilitando a integração dos conhecimentos e suas inter-relações, principalmente nos cadernos destinados a alfabetização, que abordam conteúdos de português e matemática no mesmo volume. Ademais, observaram-se tentativas de incentivar os estudantes a refletir sobre a realidade em que estão inseridos, os problemas de onde vivem e de sua escola.

A valorização da realidade sociocultural e ambiental é o também aspecto positivo a ser destacado nos materiais estudados, manifestada através de experimentos e investigação do entorno escolar, dos costumes, da biodiversidade e dos problemas ambientais do município. A abordagem de questões locais é importante, pois aproxima o conteúdo da realidade dos estudantes, gera relevância, propicia reflexão sobre a realidade, desenvolvimento de habilidades, aplicação do conhecimento e enfrentamento dos problemas. Ademais, a partir da 
práticas dialógicas é o cerne da EA crítica (LOUREIRO, 2007). Adicionalmente, destaca-se a considerável presença dos princípios 6 (solidariedade, igualdade e interação entre culturas) e 16 (consciência ética sobre as formas de vida), exceto no PPP, como um resultado positivo. E também, o estímulo ao pensamento crítico em algumas atividades dos materiais estudados, considerado um fator fundamental para a inserção da EA crítica na escola.

Entretanto, os materiais também compartilham limitações, uma delas é a ausência do princípio sobre o posicionamento político (princípio 4) nos cadernos pedagógicos da SME/RJ e nos livros do 'Cientistas do Amanhã'. Isso é importante, pois se uma escolha é um ato político, o não posicionamento é também interpretado como um posicionamento político.

Outra limitação é a total ausência do princípio sobre os conflitos e a justiça em todos os materiais analisados (princípio 12). Essa ausência reflete uma possível alienação dos materiais diante do cenário de violência e conflitos que vivemos na atualidade, na comunidade onde a escola está inserida, na sala de aula, e na sociedade em geral. Ademais, isso é preocupante porque a realidade local é marcada por conflitos e injustiças muito agudas. Sendo assim, é importante a consideração desse princípio de forma integrada nas práticas e nos demais materiais. A questão socioambiental atual demanda uma percepção crítica do papel dos conflitos na vida individual e coletiva, dos diferentes tipos de conflitos existentes, da necessidade de reconhecê-los e de formas de lidar com eles (CARVALHO, 2004).

O caso dos cadernos pedagógicos da prefeitura é considerado mais grave, pois o material é elaborado pelo poder público, que deveria se empenhar na aplicação das diretrizes do sistema municipal de EA, que estabelece que as questões locais fazem parte da EA (RIO DE JANEIRO, 2008). Neste estudo, conflitos são interpretados como questões locais e compõem a realidade da cidade. Também, a incorporação de um objetivo relativo a este tema no PPP seria interessante, uma vez que o mesmo se propõe a trabalhar a realidade da comunidade em que está situada, que é constituída por vários conflitos.

Adicionalmente, assim como constatado no estudo de Bonotto e Semprebone (2010), nos materiais da prefeitura analisados são propostas ações específicas aos estudantes, como por exemplo, a coleta seletiva de lixo, a redução de consumo e a informação à comunidade, com a produção de cartazes, panfletos ou anúncios sobre assuntos discutidos em classe. Esse tipo de atuação incentiva o empoderamento e o envolvimento nas questões ambientais do entorno. Porém, é importante destacar a necessidade de se incentivar a reflexão crítica desses problemas para uma a transformação da realidade, uma vez que há nos materiais uma abordagem superficial dessas questões.

Esse posicionamento político de valorizar ações individuais, notado também nos materiais da prefeitura e do 'Cientistas do Amanhã', contribui para a redução da articulação dos estudantes para a resolução de problemas de forma coletiva, e para a desvalorização das organizações populares. $O$ individualismo conduz ao egoísmo e a desumanização, assim, a solidariedade e a comunhão dos existires são importantes para a transformação das situações de opressão (FREIRE, 2014). No histórico do local estudado, a qualidade ambiental e o acesso a serviços básicos estão diretamente relacionados à mobilização popular. Diante disso, é importante a renovação desses valores coletivos. 
Por fim, uma última limitação consiste no pouco incentivo ao pensamento crítico sobre as questões socioambientais. Na maioria das propostas dos cadernos pedagógicos, as intervenções humanas na natureza não são problematizadas. Já nos livros do 'Cientistas do Amanhã', apesar da profundidade, também não são feitas reflexões sobre questões atuais relacionadas ao conteúdo e a relação homem-natureza. Novamente, a inserção da ideia de conflito pode colaborar com maior incentivo à criticidade do que o gerado por esses materiais.

Algumas poucas aulas dos materiais do 'Cientistas do Amanhã' foram contextualizadas socialmente, e ainda assim superficialmente. Por exemplo, a ausência de posicionamento sobre a discriminação racial ao se abordar o tema identidade (SANGARI DO BRASIL, 2006b) e a questão das enchentes na cidade, relacionadas à influência antrópica e à impermeabilização do solo (SANGARI DO BRASIL, 2007). Há o experimento para compreensão desse fenômeno, mas não há apontamentos de soluções e nem as razões sociopolíticas das ocupações em locais de risco.

Entretanto, é importante ressaltar que foram observadas algumas atividades profundas e críticas, e semelhança em muitas abordagens e experimentos entre os materiais. Além disso, os princípios 1 (todos são aprendizes e educadores) e 4 (ato político/transformação social), fundamentais para a construção de conhecimento no ambiente escolar, e para a transformação social, foram constatados poucas vezes.

Maria, Lopes e Tomasiello (2015), ao analisar materiais didáticos de química e o seu uso por docentes de uma escola, constataram a forte influência desses materiais nos discursos e práticas dos professores, a extrema confiança dos estudantes no conteúdo dos livros e reconheceram a liberdade das professoras para alterar os conteúdos desses materiais. Diante desse contexto, se faz importante a análise e reflexão sobre os conteúdos dos materiais didáticos e o destaque para a autonomia do professor. Assim como Maria, Lopes e Tomasiello (2015), Bonotto e Semprebone (2010) reconhecem em seus trabalhos que o papel do professor é fundamental na medida em que identifica tais limitações do material e ajuda os estudantes a refletir sobre elas, além de poder selecionar outros materiais que complementem o trabalho educativo.

\section{CONSIDERAÇÕES FINAIS}

Ao refletir se os materiais contemplam os objetivos do PPP, conclui-se que apenas parcialmente, pois os cadernos pedagógicos poderiam ser mais aprofundados e incentivar o pensamento crítico. Já os materiais do 'Cientistas do Amanhã', apesar de incorporarem a maioria dos Princípios, não coadunam com a valorização do professor proposta no PPP, uma vez que, da forma como propõem suas atividades, desvalorizam o trabalho intelectual e criativo do docente.

Adicionalmente, é importante ressaltar aqui que essas conclusões são feitas exclusivamente a partir da análise de alguns materiais utilizados na escola, o que não abrange a prática pedagógica de forma completa. A prática docente, fundamental na atribuição de sentidos ao que é feito em sala, não foi considerada. Isso significa que as limitações encontradas nos documentos 
analisados não necessariamente são transferidas para a prática cotidiana, visto que passam pelo 'crivo' docente e pela complementação de outros materiais.

Assim, é preciso que não se tomem os apontamentos aqui realizados como críticas à escola, docentes ou seu trabalho em geral. Pelo contrário, considera-se fundamental que as virtudes e limitações dos materiais analisados sejam levadas em consideração ao serem usados em aula. Isso é importante para que essas limitações sejam amplificadas e complementadas na prática, com a experiência, leitura crítica e o conhecimento dos educadores (as).

Ressalta-se também a importância da autonomia e da formação dos professores (as) para que refinem suas condições para perceber e inserir os princípios do Tratado nas suas práticas, além de avaliar os materiais didáticos, buscando complementações.

Conclui-se assim, portanto, que os materiais didáticos analisados coadunam com alguns dos princípios do Tratado de Educação Ambiental para Sociedades Sustentáveis e Responsabilidade Global. Destaca-se nesses resultados a total ausência dos princípios que abordam a questão dos conflitos e da justiça, que deveriam fazer parte de forma mais consciente do PPP, dos materiais utilizados e do fazer da escola. Também, é importante ressaltar que dos materiais analisados o PPP foi o mais alinhado com os princípios da EA. Já entre os materiais didáticos, o livro 'Solos' do projeto Cientistas do Amanhã foi o mais se alinhou ao Tratado.

Além disso, é importante que os materiais didáticos, as práticas pedagógicas, a formação das educadoras e os documentos institucionais direcionadores do fazer escolar estejam alinhados uns com os outros. Sugere-se aqui, para tal, que os Princípios da Educação Ambiental constituam essa espinha dorsal, para que as ações escolares se apoiem umas às outras de forma cada vez mais consciente, e que busquem, cada vez mais em conjunto, a sua realização.

\section{AGRADECIMENTOS}

Agradecemos à Pró-Reitoria de Extensão e Cultura, PROExC, da Universidade Federal do Estado do Rio de Janeiro, pela bolsa de extensão que possibilitou a vivência da primeira autora deste trabalho na escola, a partir da qual emergiu seu projeto de pesquisa; e ao Conselho Nacional de Desenvolvimento Científico e Tecnológico, CNPQ, pela bolsa de mestrado da primeira autora. Somos também gratos à escola em que o trabalho foi realizado, suas diretoras, coordenadora pedagógica e professoras, pelo acolhimento e apoio durante todo o processo. 


\title{
Teaching materials used at a municipal school in Rio de Janeiro, considerations in the light of the treaty on environmental education
}

\begin{abstract}
This essay aims to understand whether teaching materials used at a municipal school Rio de Janeiro incorporates the environmental education principles established by the Treaty on Environmental Education for Sustainable Societies and Global Responsibility. To this end, this research applied content analysis to three materials, the school's PoliticalPedagogical Project, issues of the municipal 'Cadernos Pedagógicos' and issues the 'Cientistas do Amanhã' collection, all in the light. The results indicate that such materials, in general, encourage science education and lack critical and political approaches of local environmental conflicts and justice. Nevertheless, it concludes that the documents analyzed align with some principles of the Treaty. Finally, it understands the importance that teaching materials, pedagogical practices, the training of teachers and the guiding institutional documents of the school are integrated with each other, and that the principles on environmental education can be the basis for this integration.
\end{abstract}

KEYWORDS: Formal environmental education. Content analysis. Conflicts. 
I Índices extraídos do Tratado de Educação Ambiental para sociedades Sustentáveis e Responsabilidade Global (FÓRUM..., 1992).

II A sigla PPP significa 'Projeto Político Pedagógico' e os itens $\left(X^{1}, X^{2}, X^{3}, X 4, X 5, X\right.$ 6) dessa coluna referem-se às seções do documento: $X 1$ - objetivos gerais; $X 2$ objetivos específicos do PPP; X3 - metodologia do PPP -; X4- metas do PPP; X5 avaliação e X6 - entendendo a nossa escola.

III A sigla 'CP' significa "cadernos pedagógicos", os números ordinais que a acompanham indicam as séries do ensino fundamental a que o material se destina.

IV O Projeto Político Pedagógico não será referenciado para preservar o anonimato da escola.

\section{REFERÊNCIAS}

ANDRADE, D. F. de. A importância da discussão da condição profissional do docente na formação continuada em Educação Ambiental. Revista de Educação Pública, v. 18, n. 38, p.535-550, 2009.

ANDRADE, D. F.de; SORRENTINO, M. Da gestão ambiental à educação ambiental: as dimensões subjetiva e intersubjetiva nas práticas de educação ambiental. Pesquisa em Educação Ambiental, vol. 8, n. 1 - p. 88-98, 2013.

BARDIN, L. Análise de conteúdo. Lisboa: Edições 70, 1977.

BRASIL. Lei 9.795, de 28 de abril de 1999. Dispõe sobre Educação Ambiental e institui a Política Nacional de Educação Ambiental, e dá outras providências. Diário Oficial da União, Brasília, 1999.

BONOTTO, D. V. B.; SEMPREBONE, A. Educação ambiental e educação em valores em livros didáticos de ciências naturais. Ciência \& Educação, v. 16, n. 1, 2010, p. 131-148. Recuperado de http://hdl.handle.net/11449/20639

CARVALHO, I. C. M. Educação Ambiental Crítica: nomes e endereçamentos da educação. In: Layrargues, P.P (Coord.). Identidades da educação ambiental brasileira. Brasília: MMA/DEA, 2004, p. 13-24.

FIGUEIREDO, T. F.; PINHEIRO, V. H. S.; ZAÚ, A. S. Aprender Brincando com a Natureza: experiências de educação ambiental em uma escola municipal pública, em uma comunidade de baixa renda. RETTA - Revista de Educação Técnica e Tecnológica em Ciências Agrícolas, v. 6, n. 9, p. 149-169, 2014. 
FÓRUM INTERNACIONAL DE ORGANIZAÇÕES NÃO GOVERNAMENTAIS E MOVIMENTOS SOCIAIS. Tratado das ONGs: aprovados no Fórum Internacional de Organizações Não Governamentais e Movimentos Sociais, no âmbito do Fórum Global: Eco 92. Organização editorial Ana Lucia La Rovere e Liszt Vieira. Rio de Janeiro: Instituto de Ecologia e Desenvolvimento, p. 198- 201, 1992.

FREIRE, P. Pedagogia do oprimido. 58 ed. Rio de Janeiro, Paz e Terra, 2014.

FREIRE, P. Pedagogia da Autonomia: saberes necessários a prática educativa. 53 ed, Paz e Terra, Rio de Janeiro, 2016.

GUIMARÃES, M. Educação ambiental: participação para além dos muros da escola. In: Mello, S.; Trajber, R. (Org.). Vamos cuidar do Brasil: conceitos e práticas em educação ambiental. 1 ed. Brasília: MEC/UNESCO, v. 1, p. 85-93, 2007.

LAJOLO, M. Livro didático: um (quase) manual de usuário. In: MEC. Em Aberto Livro didático e qualidade do ensino, Brasília, v. 16, n. 69, p. 3-7, 1996.

LOUREIRO, C. F. B. Educação ambiental crítica: contribuições e desafios. In: MELLO, S. S.; TRAJBER, R. (coord.). Vamos cuidar do Brasil: conceitos e práticas em educação ambiental na escola - Brasília: Ministério da Educação, Coordenação Geral de Educação Ambiental: Ministério do Meio Ambiente, Departamento de Educação Ambiental: UNESCO, 2007, p. 65 - 72.

MARIA, C. J.; LOPES, J. B.; TOMMASIELLO, M. G. C. Influência do "Caderno de Química" em práticas de ensino em sala de aula. Ciência \& Educação, Bauru, v. 21, n. 2, p. 329-349, 2015 . Doi: http://dx.doi.org/10.1590/1516731320150020005

MARPICA, N. S.; LOGAREZZI, A. J. M. Um panorama das pesquisas sobre livro didático e educação ambiental. Ciência \& Educação, v. 16, n. 1, p. 115-130, 2010

MEC. A Implantação da Educação Ambiental no Brasil, Brasília - DF, 1998

PICCININI, C. L. 'Cientistas do Amanhã': parceria público-privada na formação científica municipal no Rio de Janeiro. Atas do IX Encontro Nacional de Pesquisa em Educação em Ciências - IX ENPEC Águas de Lindóia, SP - 10 a 14 de novembro, 2013. municipal de educação ambiental e dá outras providências. Diário Oficial do Município. Rio de Janeiro, 2008. 
- Caderno pedagógico da prefeitura do Rio de Janeiro. Primário carioca. Alfabetização, 10 ano (10 bimestre; 2ㅇ bimestre; 3 bimestre e 4일 bimestre), 2014a. Disponível em: <http://www.rioeduca.net/recursosPedagogicos.php>. Acesso em 04 de outubro de 2015.

Caderno pedagógico da prefeitura do Rio de Janeiro. Primário carioca. Alfabetização, 2 ano, (10 bimestre, 20 bimestre, 3 bimestre e 4 bimestre) 2014b. Disponível em: <http://www.rioeduca.net/recursosPedagogicos.php>. Acesso em 04 de outubro de 2015.

Caderno pedagógico da prefeitura do Rio de Janeiro. Primário carioca. Alfabetização, 3 ano, (10 bimestre, 20 bimestre, 3 bimestre e 4 bimestre), 2014c. Disponível em: <http://www.rioeduca.net/recursosPedagogicos.php>. Acesso em 04 de outubro de 2015.

Caderno pedagógico da prefeitura do Rio de Janeiro. Primário carioca Ciências, 4 ano (10 bimestre, 20 bimestre, 3ㅇ bimestre e 4ㅇ bimestre), 2014d. Disponivel em: <http://www.rioeduca.net/recursosPedagogicos.php>. Acesso em 04 de outubro de 2015.

Caderno pedagógico da prefeitura do Rio de Janeiro. Primário carioca Ciências, 50 ano (1ㅇ bimestre, 2ㅇ bimestre, 3 bimestre e 4 bimestre), 2014e. Disponível em: <http://www.rioeduca.net/recursosPedagogicos.php >. Acesso em 04 de outubro de 2015.

Caderno pedagógico da prefeitura do Rio de Janeiro. Primário carioca. Alfabetização, 10 ano (10 bimestre, 20 bimestre, 3o bimestre e 40 bimestre), 2015a. Disponível em: <http://www.rioeduca.net/recursosPedagogicos.php>. Acesso em 04 de outubro de 2015.

Caderno pedagógico da prefeitura do Rio de Janeiro. Primário carioca. Alfabetização, 20 ano, (10 bimestre, 20 bimestre, 3ㅇ bimestre e 4ㅇ bimestre), 2015b. Disponível em: <http://www.rioeduca.net/recursosPedagogicos.php>. Acesso em 04 de outubro de 2015.

Caderno pedagógico da prefeitura do Rio de Janeiro. Primário carioca. Alfabetização, 3 ano, (10 bimestre, 20 bimestre, 3 bimestre e 4ㅇ bimestre), 2015c. Disponível em: <http://www.rioeduca.net/recursosPedagogicos.php>. Acesso em 04 de outubro de 2015.

Caderno pedagógico da prefeitura do Rio de Janeiro. Primário carioca Disponível em: <http://www.rioeduca.net/recursosPedagogicos.php>. Acesso em 04 de outubro de 2015. 
Caderno pedagógico da prefeitura do Rio de Janeiro. Primário carioca Ciências, 5ㅇ ano (1으 bimestre, 2으 bimestre, 3ㅇ bimestre e 4ㅇ bimestre), 2015e. Disponível em: <http://www.rioeduca.net/recursosPedagogicos.php>. Acesso em 04 de outubro de 2015.

ROCHA, E. F.; SANTOS, E. D. Ensino de Ciências e Educação Ambiental: atividades experimentais no Ensino Fundamental. Ciência em foco, Campinas, SP, v. 1, n. 3, p. 1 - 5, 2010. Disponível em: http://ojs.fe.unicamp.br/ged/cef/article/view/4492

RODRIGUES, A. R. S. Educação ambiental em tempos de transição paradigmática: entrelaçando saberes "disciplinados". Ciência \& Educação, Bauru, v. 20, n. 1, p. 195-206, 2014. Doi: http://dx.doi.org/10.1590/1516-731320140010012

SANGARI DO BRASIL. Ciclos de Vida: livro do professor. Obra elaborada pela Equipe de Pesquisa e Desenvolvimento da Sangari Brasil. 10.ed. São Paulo: Sangari do Brasil, - (CTC: Ciência e Tecnologia com criatividade), 2006a.

Corpo Humano: livro do professor. Obra elaborada pela Equipe de Pesquisa e Desenvolvimento da Sangari Brasil. 10. ed. São Paulo: Sangari do Brasil, - (CTC: Ciência e Tecnologia com criatividade), $2006 \mathrm{~b}$.

Vida das plantas: livro do professor. Obra elaborada pela Equipe de Pesquisa e Desenvolvimento da Sangari Brasil. 10.ed. São Paulo: Sangari do Brasil, - (CTC: Ciência e Tecnologia com criatividade), 2006c.

Solo: livro do professor. Obra elaborada pela Equipe de Pesquisa e Desenvolvimento da Sangari Brasil. 10.ed. São Paulo: Sangari do Brasil - (CTC: Ciência e Tecnologia com criatividade), 2007. 
Recebido: 2018-05-29

Aprovado: 2018-12-09

DOI: $10.3895 /$ rbect.v12n2.8332

Como citar: FIGUEIREDO, T. F.; ANDRADE, D. F. Materiais didáticos usados em uma escola municipal do Rio de Janeiro, um olhar à luz do tratado da educação ambiental. Revista Brasileira de Ensino de Ciência e Tecnologia, v. 12, n. 2, 2019. Disponível em: <https://periodicos.utfpr.edu.br/rbect/article/view/8332>. Acesso em: xxx.

Correspondência: Tainá Figueroa Figueiredo - tainaff12@gmail.com

Direito autoral: Este artigo está licenciado sob os termos da Licença Creative Commons-Atribuição 4.0 Internacional. 